\title{
HIDROGENOFOSFATO DE TITÂNIO LAMELAR: SÍNTESE, TROCA IÔNICA E INTERCALAÇÃO
}

\author{
Liliane M. Nunes
}

Departamento de Química, Universidade Federal da Paraíba, CP 5093, 58059-900 João Pessoa - PB

Claudio Airoldi*

Instituto de Química, Universidade Estadual de Campinas, CP 6154, 13083-970 Campinas - SP

Recebido em 28/7/00; aceito em 4/4/01

\begin{abstract}
LAMELLAR TITANIUM HYDROGENPHOSPHATE: SYNTHESYS, ION-EXCHANGE AND INTERCALATION. The development associated with the research field involving crystalline inorganic lamellar titanium hydrogenphosphate, $\mathrm{Ti}\left(\mathrm{HPO}_{4}\right) \cdot \mathrm{H}_{2} \mathrm{O}$, synthesized as alpha or gamma forms, is directly linked to the huge number of reactions, that occur inside the free interlamellar space. Two distinguishable well-characterized features such as ion-exchange and intercalation reactions are explored here. From the interactive point of view, the acidic $\mathrm{OH}$ centres distributed on the lamella can interact with cations or with basic polar molecules to exchange or to intercalate them. These chemical reactions are normally followed by an expansion of the interlamellar space, proportional to the amount intercalated, reflecting in ion radii or organic molecule size lengths used in ion-exchange or insertion processes, respectively. The effectiveness of the exchange increased when the original matrix has the proton of $\mathrm{OH}$ group previously ion-exchanged by an alkaline or an alkylammonium cations. Monoalkyl-, dialkyl- and heterocyclic amines are focused in this revision as clear and elucidative examples of acid-base interactive processes, that come out inside of the well-formed infinite sequence of inorganic lamellar structure.
\end{abstract}

Keywords: titanium hydrogenphosphate; lamellar; intercalation; ion-exchange; amine.

\section{INTRODUÇÃO}

Um considerável número de compostos inorgânicos de características cristalinas tais como grafita, argilas, fosfatos, fosfonatos, arsenatos, oxicloretos e sulfeto metálicos, óxidos de metais de transição, etc, despertam elevado interesse em virtude das inerentes propriedades químicas, destacando-se dentre elas, os comportamentos relacionados às trocas iônicas de grupos ácidos da superfície e ao processo de intercalação que ocorre no interior da lamela ${ }^{1}$.

A aplicação de materiais no processo de troca iônica surgiu com o uso de produtos naturais como argilas, zeólitos e ácido húmicos no tratamento de água. No entanto, o primeiro trocador iônico utilizado comercialmente foi o gel aluminossilicato amorfo, muito embora o mesmo apresente instabilidade química diante de soluções ácidas ${ }^{2}$.

Após a segunda guerra mundial, com o avanço da tecnologia nuclear, iniciou-se a busca de materiais que pudessem realizar a troca iônica e que permanecessem estáveis até à temperatura de $423 \mathrm{~K}$. Sendo assim, toda atenção foi voltada aos óxidos hidratados pelo fato de que uma vez formados em solução, podem arrastar vários íons, durante o processo de precipitação. Dentre eles, destacam-se em particular, os óxidos de zircônio e silício. Entretanto, estes óxidos apresentam uma baixa capacidade de troca, que varia entre 1,0 a 2,0 $\mathrm{mmol}$ por grama do trocador $\left(\mathrm{g}^{-1}\right)$ e ainda podem funcionar como trocadores, tanto aniônico como catiônico ${ }^{2}$.

$\mathrm{Na}$ busca por um material com capacidade de troca iônica superior aos óxidos, chegou-se à conclusão que os mesmos quando combinados com fosfatos, arsenatos, antimonatos, molibdatos ou vanadatos aumentam esta propriedade trocadora, resultando numa capacidade superior aos óxidos de ori$\mathrm{gem}^{2}$. Contudo, estes materiais quando preparados apresentamse como amorfos e também as suas sínteses são de difícil reprodutibilidade, além de serem hidrolisados em meio alcali-

"airoldi@iqm.unicamp.br no ou em água quente. Dentre estes materiais, a atenção maior foi dada ao hidrogenofosfato de zircônio, em virtude de desempenhar uma aplicabilidade útil, como na adsorção em diálise renal ${ }^{2}$.

Um grande volume de trabalhos foi dedicado à troca iônica até meados da década de sessenta, quando foi publicada a primeira síntese do fosfato de zircônio cristalino ${ }^{3}$, o qual surgiu como um marco importante no papel do desenvolvimento da Química e em particular com a Química Inorgânica. A rota de síntese inicial consistiu em partir de composto com estrutura amorfa, a qual transformava em cristalina lamelar no longo processo sintético. Estava aberto assim, devido ao comportamento químico, um novo caminho para a obtenção de vários outros fosfatos de metais tetravalentes.

Tanto o hidrogenofosfato como o hidrogenoarsenato de metais tetravalentes, que serão denominados daqui para frente sem o prefixo hidrogeno, apresentam-se como sais ácidos insolúveis em água, com fórmula geral do tipo $\mathrm{M}\left(\mathrm{HXO}_{4}\right)_{2} \cdot \mathrm{nH}_{2} \mathrm{O}(\mathrm{M}$ $=\mathrm{Zr}, \mathrm{Ti}, \mathrm{Sn}, \mathrm{Ce}, \mathrm{Hf}, \mathrm{Pb}, \mathrm{Si}$, etc, e $\mathrm{X}=\mathrm{P}, \mathrm{As})$. Estes sais lamelares são isoestruturais ${ }^{1,4-6}$, sendo considerados como excelentes matrizes para reações de troca ${ }^{1,2,4,7}$ e intercalação ${ }^{1,4,7}$ 9 , apresentando alta capacidade de troca iônica, que pode variar desde 4,0 até $8,0 \mathrm{mmol} \mathrm{\textrm {g } ^ { - 1 }}$ para cátions monovalentes ${ }^{1,4,7,10}$. No caso particular do fosfato de titânio a capacidade de troca iônica para cátions monovalentes corresponde a 7,76 e 7,25 mmol g-1 para as formas cristalinas denominadas alfa $(\alpha)$ e gama $(\gamma)$, respectivamente ${ }^{1}$.

\section{ESTRUTURA DO FOSFATO DE TITÂNIO}

As estruturas cristalinas destes tipos de fosfatos podem ser exemplificadas através da estrutura de um composto representativo, que normalmente escolhe-se o fosfato de zircônio, na forma alfa, como visto na Figura 1. A estrutura é composta por um plano de átomos do metal ligados entre si por pontes de ânions fosfatos, formando uma cadeia inorgânica infinita, cujo conjunto de átomos define um plano, também denominado como lamela. Cada átomo metálico 
nesta lamela está octaedricamente coordenado com seis grupos fosfatos. Na estrutura formada dos quatro oxigênio de cada fosfato, três deles estão ligados a três diferentes átomos do metal. Logo, o oxigênio remanescente liga-se a um próton que posiciona-se dentro do espaço lamelar, ficando então disponível para atuar diretamente com base para estabelecer ligações, no composto intercalado ${ }^{1,11}$.

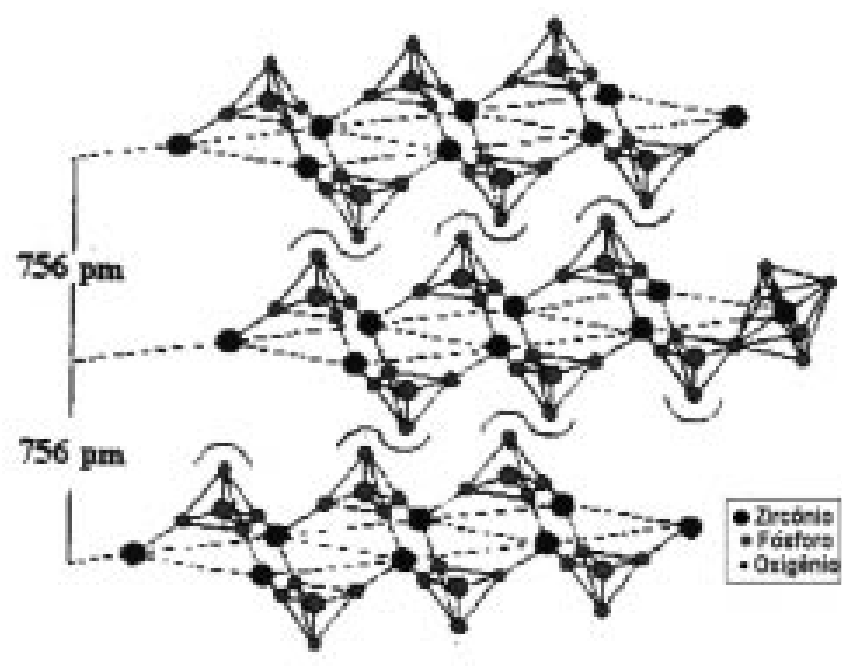

Figura 1. Representação da estrutura do hidrogenofosfato de zircônio na forma alfa.

O arranjo dos grupos fosfatos na estrutura cristalina organizada provoca o aparecimento de cavidades do tipo zeolítica em ambas as faces da lamela. Estas podem acomodar moléculas de água através de ligações de hidrogênio, devido à participação efetiva do grupo $\mathrm{OH}$, mas mesmo assim, permitem a difusão no espaço livre, de partículas esféricas no interior dessas cavidades, cujo tamanho teórico estimado é de $261 \mathrm{pm}^{1,4}$.

As lamelas do fosfato de titânio na forma alfa com distância interplanar de $756 \mathrm{pm}$, são mantidas agrupadas em seqüência infinita, através de forças fracas de van der Waals. Este arranjo cristalino cria uma condição de disponibilidade de espaço bidimensional expansível no interior das lamelas ${ }^{1}$.

O composto com estrutura lamelar do tipo $\gamma$ é caracterizado por apresentar uma distância interplanar maior em relação à forma cristalina $\alpha$. Dentre os diferentes fosfatos do tipo $\gamma$, os compostos com zircônio e titânio são os mais estuda$\operatorname{dos}^{12,13}$. A diferença na distância interlamelar deve-se à presença de grupos fosfatos e de hidrogenofosfatos, em proporções equivalentes na matriz, que induzem à uma conformação espacial do metal e dos grupos fosfatos de maneira distinta à descrita para a forma $\alpha$. Além disto, existem duas moléculas de água no espaço interlamelar, que necessitam de um arranjo, provocando um maior afastamento das lamelas para acomodá-las, causando assim, uma distância interlamelar de 1160 pm. Mesmo contando com uma diversidade de técnicas de caracterização, uma descrição mais precisa do arranjo espacial desta estrutura cristalina só foi definitivamente esclarecida nesses últimos dez anos ${ }^{14,15}$.

As condições de síntese influenciam no grau de cristalinidade destes materiais, possibilitando a obtenção de uma das duas formas cristalinas mais estáveis, que são as já mencionadas alfa $(\alpha)$ e gama $(\gamma)^{1,4,16}$, além das quais várias outras formas semicristalinas possam também ser caracterizadas ${ }^{17-21}$. Os difratogramas de raios $X$ apresentados nas Figuras $2 a$ e $2 b$, mostram a excelente cristalinidade dos fosfatos lamelares nas formas alfa e gama, respectivamente.

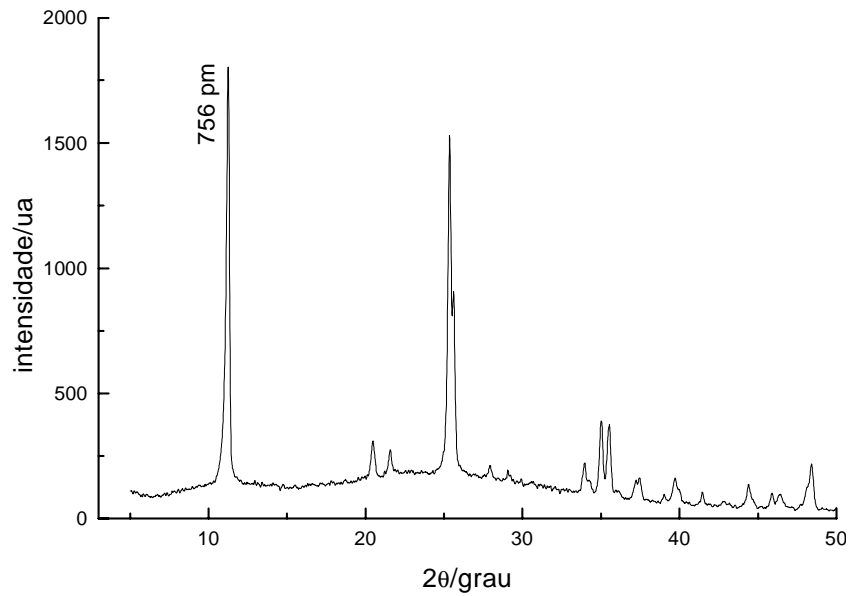

(a)

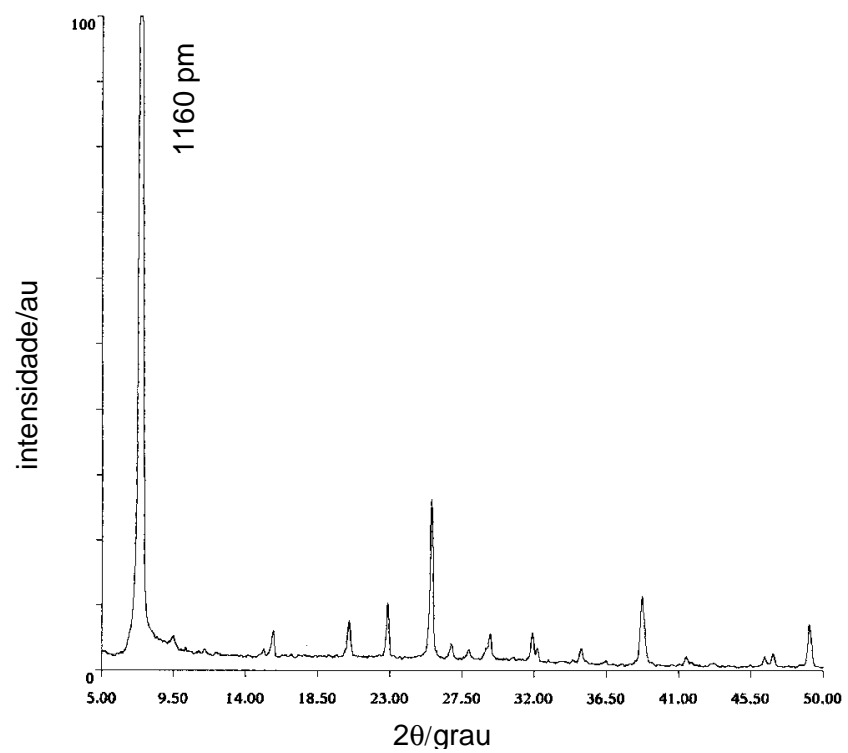

(b)

Figura 2. Difratograma de raios $X$ dos fosfatos lamelares de titânio nas formas (a) alfa e (b) gama.

\section{METODOS DE SÍNTESE DOS FOSFATOS LAMELARES DE TITÂNIO}

\section{Fosfato de titânio amorfo}

O procedimento preparativo que parte do fosfato amorfo é sem dúvida o mais utilizado para se obter o fosfato lamelar de titânio. Inicialmente, é necessária a preparação de material amorfo com características apropriadas, o qual consiste na adição lenta da solução ácida de tetracloreto de titânio à uma solução aquosa de hidrogenofosfato dissódico, sob agitação constante, na proporção 1:2. O pH da solução deve ser monitorado e ajustado em 2,0 por adição cuidadosa de hidróxido de sódio, formando assim um gel $1^{11,22,23}$.

Um fato marcante relacionado à síntese é que os fosfatos nas formas alfa e gama diferem apenas na concentração do ácido fosfórico utilizado no refluxo. Para a preparação do primeiro $^{11,22,23}$, o fosfato amorfo é então dissolvido em ácido fosfórico entre 10,0 a 14,0 mol dm${ }^{-3}$. Enquanto que, para a obtenção do segundo $^{24-26}$ a concentração do ácido deve estar na faixa entre 15,0 a $17,0 \mathrm{~mol} \mathrm{dm}^{-3}$. O grau de cristalinidade aumenta com o aumento do tempo dispendido em refluxo e com a crescente concentração do ácido fosfórico ${ }^{1,4}$. Porém, uma desvantagem 
deste método é o uso de concentrações elevadas do ácido e o longo tempo de reação, que chega por volta de 100 h.

\section{Precipitação com ácido fluorídrico}

Esta síntese ocorre entre a mistura de uma solução aquosa de tetracloreto de titânio em ácido clorídrico, ácidos fluorídrico e fosfórico ${ }^{27-29}$. A grande vantagem consiste nas condições de temperatura relativamente baixa, a $333 \mathrm{~K}$ quando comparada com síntese anterior. Por outro lado, como já mencionado, a concentração do ácido fosfórico vai determinar a formação das diferentes fases alfa ou gama. Entretanto, vários inconvenientes ocorrem neste método, tais como: a cristalinidade do material obtido não é elevada e a velocidade no processo de formação do fosfato é lenta, devido à estabilidade do complexo intermediário fluoro-titânio, sendo assim, estes inconvenientes contribuem para que este método seja menos utilizado na obtenção do fosfato de titânio cristalino ${ }^{30}$.

\section{Oxidação de titânio (III)}

O passo determinante para alcançar o sucesso deste método está relacionado à eficiência da oxidação do cátion titânio (III). Para tanto, prepara-se uma mistura de tricloreto de titânio com ácido fosfórico na presença de um oxidante, sendo mais comumente utilizados peróxido de hidrogênio, oxigênio gasoso ou ar comprimido. As formas do fosfato alfa ou gama, a ser sintetizado depende da razão molar entre fósforo:titânio, da concentração do ácido e da temperatura ${ }^{30-32}$. Este método é relativamente pouco explorado, embora, o material obtido apresenta excelente cristalinidade.

\section{Óxido de titânio}

Este método preparativo utiliza-se do óxido de titânio como fonte de material de partida, o qual é suspenso em ácido fosfórico concentrado e a mistura é refluxada ${ }^{6}$. Aparentemente, trata-se de um método simples, mas, propício para a obtenção da forma alfa, mas, o composto final com baixa cristalinidade é a principal desvantagem deste método de síntese.

\section{Reação hidrotérmica}

A reação hidrotérmica é a mais utilizada para se ter a formação da fase cristalina gama ${ }^{26,33}$, sendo um dos métodos no qual o material sintetizado apresenta maior cristalinidade. Um fator preponderante a ser considerado é a utilização de baixa concentração de ácido fosfórico. Como em outras sínteses, esta também parte do fosfato amorfo, o qual é posto em reação com ácido fosfórico $10,0 \mathrm{~mol} \mathrm{\textrm {dm } ^ { - 3 }}$ e levado à uma bomba hidrotérmica para a efetivação da síntese.

\section{TROCA IÔNICA}

Os primeiros estudos com fosfatos cristalinos foram realizados com intuito de se verificar o comportamento do mesmo frente ao processo de troca. As reações de trocas iônicas com estes compostos ocorrem entre os prótons ligados aos grupos $\mathrm{P}-\mathrm{OH}$ livres do fosfato, que estão dispostos no interior das cavidades da estrutura inorgânica lamelar, com os cátions metálicos, normalmente dissolvidos em solução aquosa. O final da troca ocorre o equilíbrio do sistema, implicando inclusive na manutenção de cargas, fenômeno que acontece na interface sólido/líquido, sem provocar quaisquer mudanças físicas estruturais na lamela. Nesta troca o próton do grupo $\equiv \mathrm{P}-\mathrm{OH}$ da rede cristalina é equivalentemente substituído pelo cátion $\mathrm{M}^{\mathrm{n}+}$ como pode ser visualizado na reação abaixo:

$$
\mathrm{n} \equiv \mathrm{P}-\mathrm{OH}+\mathrm{M}^{\mathrm{n}+}=(\equiv \mathrm{P}-\mathrm{O})_{\mathrm{n}} \mathrm{M}^{\mathrm{n}+}+\mathrm{nH}^{+}
$$

Os compostos lamelares apresentam facilidade em acomodar espécies entre as lamelas, podendo causar um aumento da distância interplanar. No simples caso envolvendo a troca iônica, este fenômeno só será possível se ocorrer difusão dos cátions no espaço entre as lamelas, para que favoreça a troca com os prótons da matriz. Este processo começa na parte externa do cristal e prossegue paulatinamente para atingir o interior das lamelas. Dependendo das características catiônicas, este fenômeno pode alterar a distância interplanar ${ }^{4}$. Uma expansão inicial desta distância é necessária para que possa ocorrer a troca, no sentido de acomodar não somente os cátions, como também, as moléculas de água de hidratação, as quais forçosamente acompanham os mesmos. Enquanto o processo de troca estiver incompleto, pode haver a coexistência de mais de uma fase, sendo que a nova fase formada pode apresentar uma distância interplanar maior que a original ${ }^{2}$, como mostrado na Figura 3. Este fenômeno foi observado na troca iônica dos prótons com ambas formas dos fosfatos de titânio com o cátion sódio $^{34,35}$. Na troca envolvendo a forma alfa observou-se a coexistência de três fases do trocador, sendo que uma delas apresentou a distância interplanar de 760 pm, ou seja, a distância original da matriz, e as outras duas em 1040 e 990 pm, que foram atribuídas às fases $\mathrm{TiHNa}\left(\mathrm{PO}_{4}\right)_{2} \cdot 4 \mathrm{H}_{2} \mathrm{O}$ e $\mathrm{Ti}\left(\mathrm{NaPO}_{4}\right)_{2} .3 \mathrm{H}_{2} \mathrm{O}$, respectivamente, como mostra o difratograma de raios $\mathrm{X}$ apresentado na Figura 4. Desta forma, o que ocorre é que numa determinada região dá-se a troca de $50 \%$ de prótons e em outra esta mesma troca é total, porém, constata-se que as novas formas trocadas contêm um aumento no número de moles de água de hidratação.

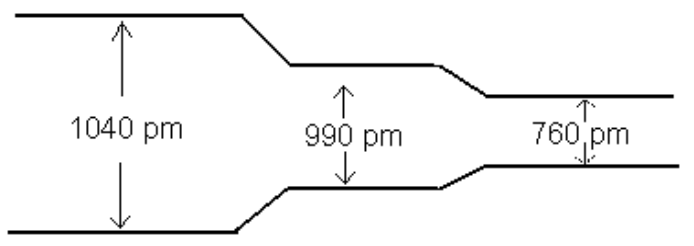

Figura 3. Representação esquemática da coexistência de diferentes fases no processo de troca iônica do ín sódio em hidrogenfosfato de titânio da forma alfa.

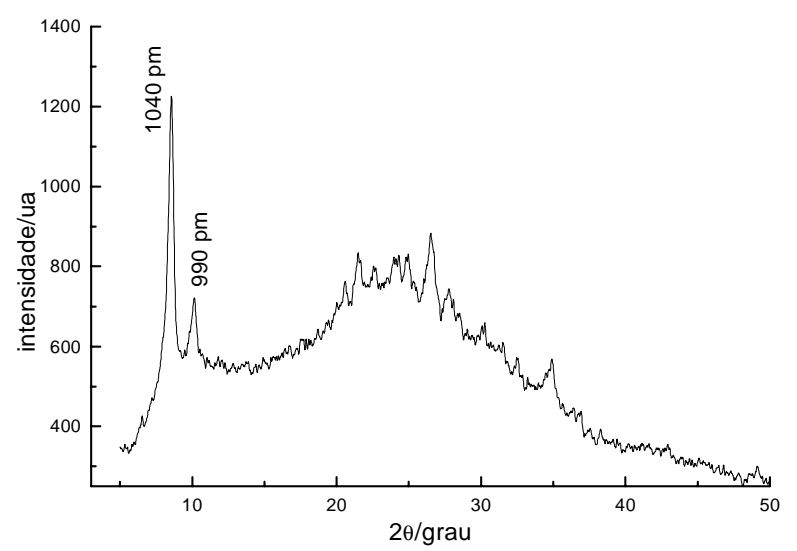

Figura 4. Difratograma de raios $X$ da modificação do alfa fosfato de titânio com sódio.

O mecanismo proposto para a troca envolve a difusão de íons não hidratados, ou até parcialmente hidratados, dentro das cavidades interlamelares, provocando assim a substituição dos prótons mais ácidos dos grupos fosfatos. Numa etapa seguinte, há a difusão de moléculas de água dentro do retículo do cristal e subseqüentemente acontece a reidratação dos cátions. Desse modo, durante a troca ocorre a difusão dos íons hidratados 
dentro das cavidades do adsorbato, o que pode provocar a troca nessas distintas etapas propostas ${ }^{36,37}$.

A natureza zeolítica dos cristais e os efeitos interativos fracos do tipo van der Waals entre as lamelas, fornecem as condições estruturais necessárias, para que se proporcione uma explicação do comportamento seletivo e ocorra a expansão da distância interplanar durante a troca ${ }^{38}$.

De um modo geral, os processos de troca iônica nestes fosfatos ocorrem numa velocidade relativamente baixa, mostrando quase sempre dois patamares nas curvas de titulação da matriz com a solução do cátion a ser trocado. Porém, este comportamento é influenciado por diferentes fatores tais como: pH do meio reacional, dimensão da cavidade zeolítica, tamanho e raio de hidratação do cátion a ser trocado e a temperatura em que está acontecendo o processo de troca. Estes fatores não só contribuem para uma baixa velocidade de reação, como também em alguns casos, torna-se impossível a própria realização da troca iônica. Entretanto, pode-se aumentar a velocidade de reação ou mesmo promover a troca, utilizando-se de alguns artifícios ${ }^{4,18}$ :

a) aumentando o pH do meio por adição de um hidróxido. Desta forma, a diferença na atividade entre o próton no sólido e na fase líquida aumenta para tal nível que, os prótons são forçados a sair e consequentemente, os cátions difundem na região interplanar, para balancear as cargas negativas no interior das lamelas.

b) utilizando outro cátion como precursor para aumentar a distância interplanar. Neste caso, a difusão dos cátions metálicos passa a ser facilitada, como exemplificada na Figura 5. $\mathrm{O}$ cátion sódio previamente intercalado provoca um aumento na distância original da matriz, para viabilizar a entrada do cátion lantânio, que é maior em dimensão.

O processo de troca iônica dos cátions duros potássio, bário, cálcio e lantânio, com raios iônicos pouco diferenciados, mas, com cargas crescentes, foi efetuado com a matriz fosfato de titânio cristalino na forma alfa, e também com a mesma matriz, porém, já modificada com os cátions sódio ou butilamônio. Como é de se esperar, os resultados da troca iônica são superiores para as últimas matrizes, em relação à matriz origi$\mathrm{nal}^{32,39}$. Da mesma forma, comportamentos semelhantes foram observados na troca iônica dos cloretos, nitratos e acetatos de zinco e cobre com as mesmas matrizes, evidenciando mais uma vez a influência dos precursores intercalados com sódio ou butilamônio nos processos de troca ${ }^{40}$.

Embora os fosfatos de titânio e zircônio na forma alfa sejam isoestruturais, mesmo assim, são notados diferentes comportamentos de troca iônica ${ }^{1,4,6,41}$. A curva de titulação resultante do processo de troca do cátion $\mathrm{K}^{+}$com a forma cristalina $\alpha$ do composto de titânio, apresenta apenas uma única etapa de troca, à qual está relacionada com a total troca dos protóns. Enquanto isto, a troca com a mesma forma cristalina do fosfato de zircônio ocorre em duas etapas, ou seja, inicialmente apenas é substituído a metade dos prótons da matriz, para ser depois complementado ${ }^{42}$. Este comportamento estaria relacionado com a diferença no volume da cela unitária dos diferentes fosfatos. O volume da cela unitária do composto de zircônio é notavelmente maior que a dos outros fosfatos metálicos ${ }^{1,4,6,41}$. Este efeito é atribuído à presença de lamelas menos enrugadas nesse fosfato cristalino ${ }^{6}$.

Um fato interessante diz respeito à seletividade, sendo geralmente baixa para o de fosfato de zircônio com os cátions metálicos divalentes ${ }^{43}$. A alta adsorção de cátions divalentes como zinco, cobre, níquel e cobalto foi observado somente à temperaturas altas e com afinidade da matriz pouco diferenciada para esta sequência de cátions ${ }^{44}$.

Os compostos cristalinos lamelares do tipo $\gamma$ são mais ácidos que os correspondentes da forma $\alpha$, devido à presença de dois grupos $\mathrm{OH}$ ligados ao mesmo átomo de fósforo, apresen-
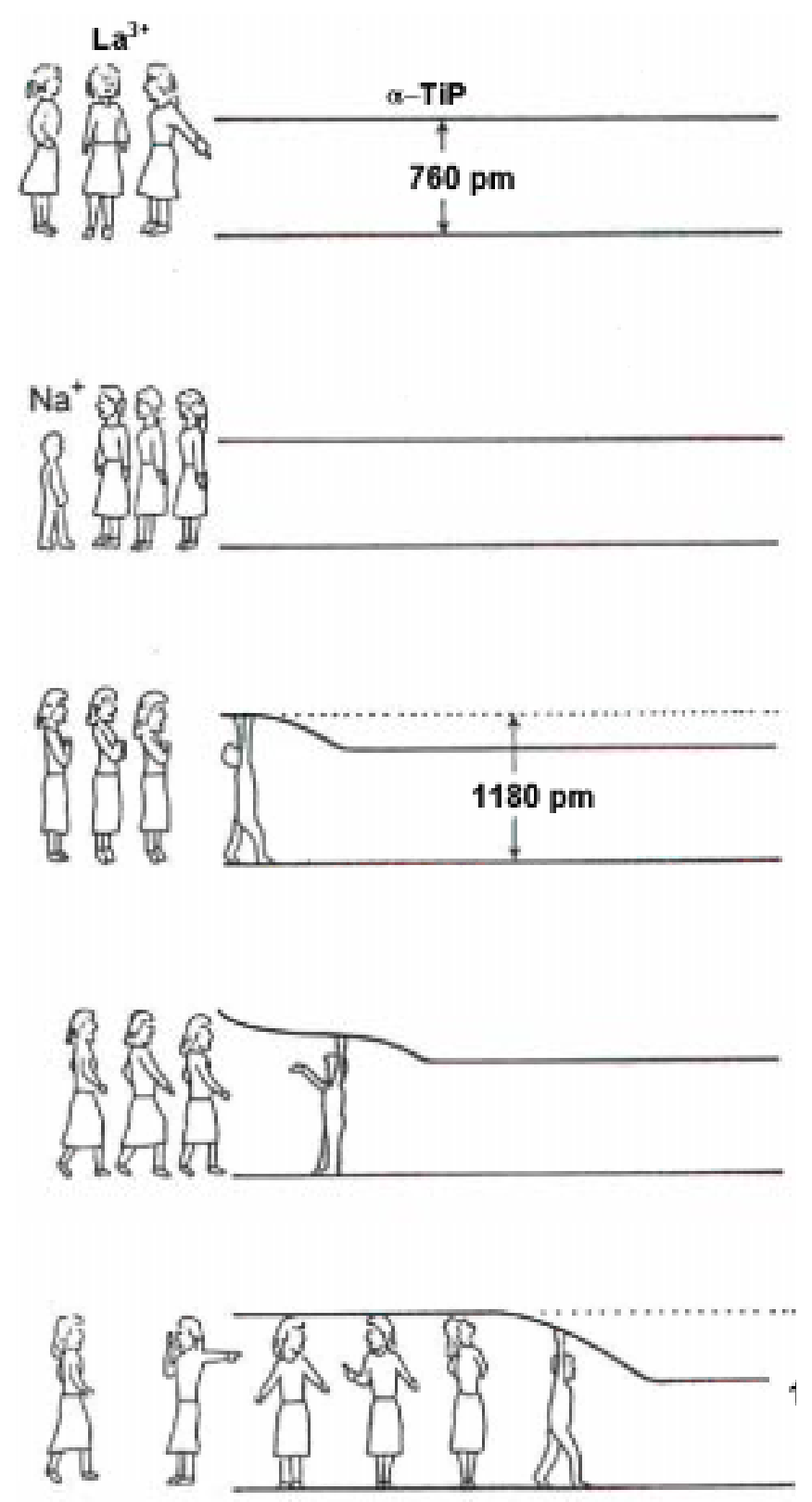

Figura 5. Representação da utilização de um cátion como precursor para aumentar a distância interlamelar, facilitando assim a difusão dos cátions metálicos a serem trocados.

tando uma distância interlamelar maior, necessária para acomodar dois moles de água por mol do composto. Devido a estes fatores, o processo de troca iônica com os fosfatos na forma $\gamma$ passam a ser favorecidos ${ }^{4,14,45-48}$, pois, a difusão dos cátions maiores ou mais hidratados como $\mathrm{Cs}^{+}, \mathrm{Ba}^{2+}, \mathrm{Rb}^{+}, \mathrm{Mg}^{2+}$, $\mathrm{Cu}^{2+}, \mathrm{Cr}^{3+}$ é superior, quando comparada com os fosfatos de forma cristalina $\alpha$. Em virtude deste aspecto de favorecimento nos processos de troca iônica, os estudos neste campo foram realizados com o fosfato de titânio na forma $\gamma$, cujos resultados mostraram-se muito mais eficientes ${ }^{49-54}$.

\section{INTERCALAÇÃO}

O termo intercalação refere-se literalmente ao ato da inserção reversível de espécies denominadas convidadas, dentro de uma matriz cristalina, que oferece condições em atuar como hóspede, cuja estrutura dispõe ainda de uma seqüência ordenada de sítios reticulares vazios ${ }^{55,56}$. 
A intercalação de moléculas convidadas entre as lamelas do hospedeiro tem aumentado consideravelmente por diversas razões $^{57-59}$. Dentre elas pode-se destacar as alterações nas propriedades ópticas e eletrônicas, tanto da matriz que recebe o intercalante, como do próprio intercalante ${ }^{57,60}$. Outra razão de estudo é devido à grande aplicabilidade desses materiais como catalisadores $^{61}$, condutores iônicos ${ }^{62}$, em eletrodos ${ }^{63}$, seletividade para certos íons ou grupos de íons ${ }^{51}$ e também por possibilitar modificação na superfície de eletrodos ${ }^{4,18,64-67}$.

A propriedade de intercalação dos fosfatos foi explorada concomitantemente à descoberta que aconteceu em 1965, com a intercalação de alquilaminas em fosfato de zircônio na forma $\alpha$, antes mesmo que se tivesse conhecimento sobre a estrutura deste fosfato cristalino ${ }^{1,4}$. Entretanto, do ponto de vista químico, toda a atenção aos fosfatos foi direcionada ao comportamento de troca iônica e nenhuma outra publicação foi relacionada ao comportamento de intercalação nestes tipos de materiais lamelares antes de $1975^{68}$. A partir da década de oitenta houve um crescente interesse neste campo, com forte reflexo no número crescente de publicações relacionadas com o comportamento de intercalação em fosfatos lamelares de titânio. Dentre as diversas moléculas polares destacam-se as aminas, como as alquilaminas ${ }^{10,22,69-72}$, alquildiaminas ${ }^{23,73,74}$ e aminas cíclicas $^{75-81}$. As Tabelas 1 e 2 mostram como a variação do número de carbonos das cadeias das aminas alifáticas ou dialquilaminas afetam as distâncias interlamelares dos fosfatos de titânio nas formas alfa e gama. Este mesmo comportamento é também verificado com uma grande sequência de aminas cíclicas na Tabela 3 .

Tabela 1. Distância interplanar (d) em pm de monoalquilaminas intercaladas em fosfatos de titânio.

\begin{tabular}{lcccc}
\hline Amina & $\alpha$-TiP & Ref & $\gamma$-TiP & Ref \\
\hline Metilamina & 1100,1290 & 72,22 & - & - \\
Etilamina & 1430,1470 & 72,22 & 1630 & 70 \\
Propilamina & 1690,1670 & 72,22 & 1840 & 70 \\
Butilamina & 1880,1860 & 72,22 & 2050 & 70 \\
Pentilamina & 2110 & 72 & - & - \\
Hexilamina & 2310 & 72 & - & - \\
Decilamina & - & - & 3400 & 70 \\
Dodecilamina & - & - & 3740 & 70 \\
Tetradecilamina & - & - & 3840 & 70 \\
Hexadecilamina & - & - & 4420 & 70 \\
Octadecilamina & - & - & 4820 & 70 \\
\hline
\end{tabular}

$\mathrm{O}$ símbolo (-) refere-se as aminas não intercaladas.
A maioria destas aminas alifáticas intercala diretamente nos fosfatos lamelares, enquanto que as moléculas cíclicas maiores, só intercalam em fosfatos após uma prévia inserção de uma base precursora. A reação de intercalação destas aminas tanto primárias $\left(\mathrm{H}_{2} \mathrm{~N}-\right)$ como aromáticas e cíclicas $(=\mathrm{N}-)$ é representada pela típica interação de neutralização ácido-base, em que o centro rico em elétrons associado à base sofre protonação do hidrogênio do grupo P-OH no interior da lamela, como pode ser representado nos esquemas abaixo:

$$
\begin{aligned}
& \equiv \mathrm{P}-\mathrm{OH}+\mathrm{H}_{2} \mathrm{~N}-\rightarrow \equiv{\mathrm{P}-\mathrm{O}^{-}{ }^{+} \mathrm{H}_{3} \mathrm{~N}-} \\
& \equiv \mathrm{P}-\mathrm{OH}+=\mathrm{N}-\rightarrow \equiv \mathrm{P}^{-\mathrm{O}^{-}}{ }^{+} \mathrm{HN} \equiv
\end{aligned}
$$

O sucesso da química de intercalação dos fosfatos lamelares é devido à presença de grupos ácidos de Brфnsted na região interlamelar ${ }^{4,46,82}$. As espécies que facilmente aceitam prótons são hóspedes preferenciais, cujo arranjo destas moléculas hóspedes na região interlamelar depende do tamanho e da forma das mesmas ${ }^{4,83}$. Durante a intercalação de uma amina, os grupos funcionais interagem com os prótons provenientes dos grupos fosfatos, fato que determina a quantidade máxima possível de amina intercalada, ou seja, dois moles de amina por unidade fórmula do fosfato lamelar ${ }^{4,84}$.

Como os efeitos interativos entre as lamelas destes compostos inorgânicos são fracas, a distância entre as mesmas pode ser facilmente aumentada, para proporcionar uma melhor acomodação das moléculas hóspedes ${ }^{1,57}$. As Figuras 6 e 7 mostram a existência de diferentes maneiras em que uma molécula orgânica polar pode se acomodar no espaço livre entre as camadas de fosfatos. Estas figuras exemplificam a intercalação de uma alquilamina e uma amina cíclica nos fosfatos de zircônio e titânio do tipo $\alpha$, respectivamente ${ }^{18,79}$. A quantidade de amina intercalada e sua geometria determinam a maneira de acomodação no espaço livre e consequentemente, o aumento na distância interlamelar.

A tendência da molécula convidada em ocupar toda a região interlamelar, a alta densidade dos grupos $\mathrm{P}-\mathrm{OH}$ distribuídos nesses espaços livres e a flexibilidade das lamelas devido às fracas forças interativas entre as mesmas, são os fatores mais importantes na definição do arranjo destas aminas no interior da lamela ${ }^{4}$.

$\mathrm{O}$ comportamento da intercalação depende de vários fatores $^{7,76,82}$, entre eles podem-se destacar o tamanho e o pKa da molécula convidada. $\mathrm{O}$ aumento na temperatura ou o uso de um solvente conveniente, muitas vezes aceleram o processo de intercalação. Quando são intercaladas bases fracas e ou mesmo moléculas grandes, torna-se necessário a utilização de matrizes previamente preparadas com precursores, tais como o sódio ou as monoaminas $1,4,18,85$.

O processo de intercalação depende, como é de se esperar, do comprimento da cadeia carbônica. Logo, para um

Tabela 2. Distância interplanar (d) em pm para dialquilaminas intercaladas em fosfatos de titânio.

\begin{tabular}{lcccc}
\hline Amina & $\alpha$-TiP & Ref & $\gamma$-TiP & Ref \\
\hline 1,2-etilenodiamina & 960,1090 & 74,23 & 1250 & 70 \\
1,3-propilenodiamina & 1040,1210 & 74,23 & 1360,1500 & 73,70 \\
1,4-butilenodiamina & 1110,1318 & 74,23 & 1430 & 73 \\
1,5-pentametilenodiamina & 1310,1424 & 74,23 & 1540 & 73 \\
1,6-hexametilenodiamina & 1420,1549 & 74,23 & 1670 & 73 \\
1,7-heptametilenodiamina & 1500 & $74,1740,1800$ & 73,70 \\
1,8-octametilenodiamina & 1580,1766 & 74,23 & 1860 & 73 \\
1,9-nonametilenodiamina & 1680,1839 & 74,23 & 1960 & 73 \\
1,10-decametilenodiamina & - & - & 2050 & 70 \\
\hline
\end{tabular}

O símbolo (-) refere-se a amina não intercalada. 
aumento no número de átomos de carbono da cadeia alifática maior que seis, o arranjo das moléculas de aminas pode ser mais complexo. Estudos com monoalquilaminas e dialquilaminas, mostram que a distância interplanar aumenta com o número de carbonos da cadeia alquila e correspondentemente diminui a quantidade intercalada ${ }^{23,73,74}$, tais comportamentos podem ser visualizados nas Figuras 8 e 9 . As monoal- quilaminas menores são rapidamente intercaladas nos fosfatos lamelares, atingindo um máximo de intercalação de dois moles de amina por mol da matriz. Neste processo forma-se uma bicamada das mesmas no espaço interlame$\operatorname{lar}^{10,69,84}$, porém, mantendo uma posição inclinada, fazendo ângulo de $56^{\circ}$ entre a cadeia da amina com o plano inorgânico definido pela camada inorgânica.

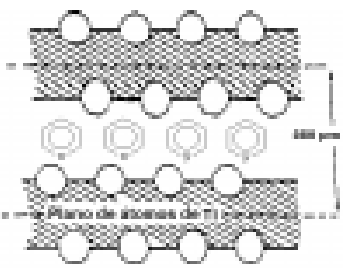

(a)

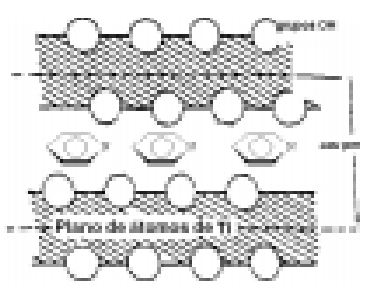

(b)

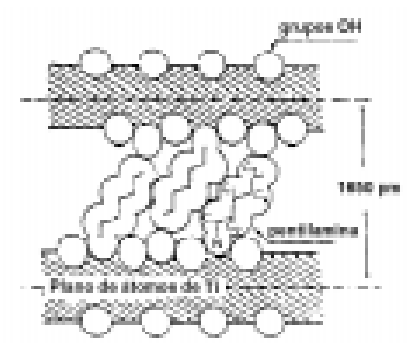

m)

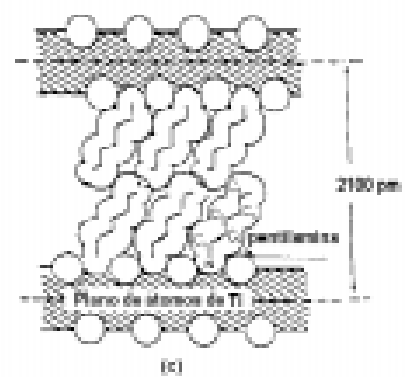

Figura 6. Representação dos diferentes arranjos que uma molécula alquilamina ao ser inserida na lamela, em posições paralela $(a)$, inclinada perpendicularmente em monocamada $(b)$ e inclinada perpendicularmente em bicamada (c).

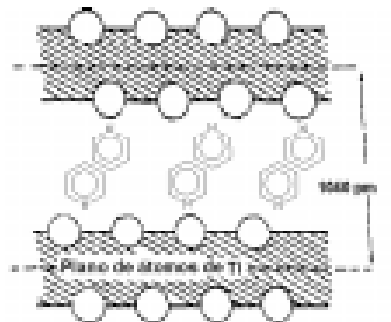

(c)

Figura 7. Representação dos diferentes arranjos da molécula orgânica piridina intercalada em hidrogenofosfato de titânio em forma alfa, em posições perpendicular formando monocamada (a), orientação paralela $(b)$ e perpendicular formando uma bicamada (c).

Tabela 3. Distância interplanar (d) em pm para as aminas aromáticas e cíclicas intercaladas em fosfatos de titânio.

\begin{tabular}{|c|c|c|c|c|}
\hline Intercalante & $\alpha-\mathrm{TiP}$ & Ref & $\gamma$-TiP & Ref \\
\hline Anilina & 1820 & 78 & 2140 & 75 \\
\hline Benzilamina & 1900 & 78 & 2120 & 75 \\
\hline Cicloexilamina & 1440 & 78 & 2150 & 75 \\
\hline Piridina & 1802,1110 & 79,78 & 1160 & 75 \\
\hline Piridazina & - & - & 1180 & 76 \\
\hline$\alpha$-picolina & 1147 & 79 & - & - \\
\hline$\beta$-picolina & 1118 & 79 & - & - \\
\hline$\gamma$-picolina & 1318 & 79 & - & - \\
\hline pirazina & amorfo, * & 78,81 & - & - \\
\hline piperidina & 1360,1660 & 78,81 & 1680 & 75 \\
\hline piperazina & amorfo, 1060 & 78,81 & 1360 & 75 \\
\hline 2,6 -lutidina & $*$ & 81 & - & - \\
\hline 2-aminopiridina & 1338,1300 & 80,76 & 1610 & 76 \\
\hline 3-aminopiridina & 1177,1180 & 80,76 & 1670 & 76 \\
\hline 4-aminopiridina & 1262,1190 & 80,76 & 1550 & 76 \\
\hline 1,4-fenilenodiamina & 1338 & 80 & - & - \\
\hline 2-amino-4-metilpiridina & 1577 & 80 & - & - \\
\hline indol & - & - & 1770 & 75 \\
\hline imidazol & amorfo & 71 & 1610 & 76 \\
\hline nicotinamida & - & - & 1700 & 76 \\
\hline benzalcônio & - & - & 2940 & 77 \\
\hline cetilpiridínio & - & - & 3270 & 77 \\
\hline benzetônio & - & - & 3150 & 77 \\
\hline tiamínio & - & - & 1160 & 77 \\
\hline 2,2-bipiridina & - & - & 1459 & 19 \\
\hline 1,10 -fenantrolina & - & - & 1746 & 19 \\
\hline 2,9-dimetil-1,10-fenantrolina & - & - & 1787 & 19 \\
\hline
\end{tabular}

Os símbolos indicam $(*)$ aminas protonadas apenas na superfície e (-) não foram intercaladas. 


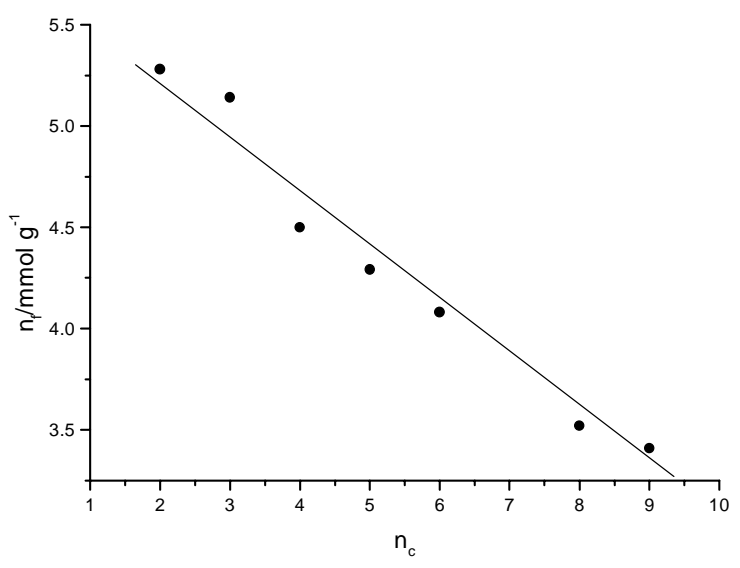

Figura 8. Correlação entre o número de moles fixos $\left(n_{f}\right)$ de dialquilamina intercalado no alfa fosfato de titânio e número de carbono da cadeia alifática $\left(n_{c}\right)$.

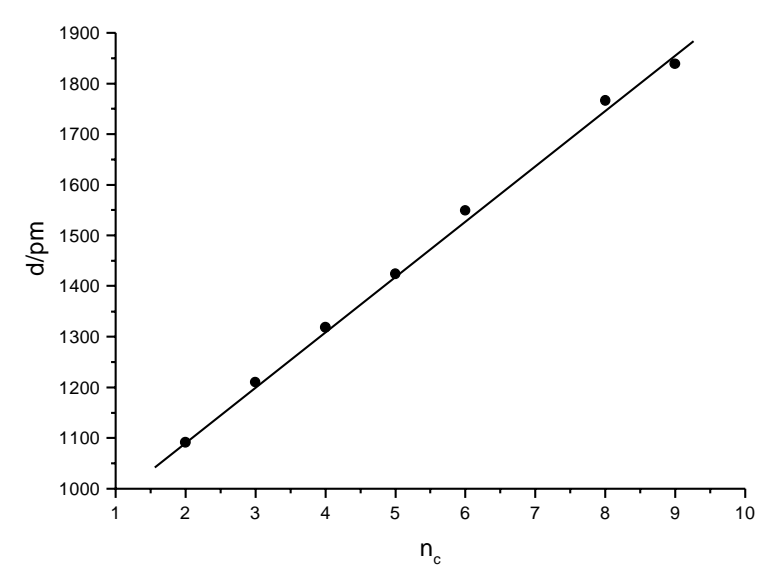

Figura 9. Correlação entre a distância interplanar (d) do alfa fosfato de titânio após intercalação com dialquilamina e o número de carbono da cadeia alifática $\left(n_{c}\right)$.

Durante o processo de intercalação de dialquilaminas nos fosfatos geram normalmente uma conformação de monocamada, com inclinação de $58^{\circ}$ no espaço interlamelar, sendo que cada molécula de diamina pode interagir com dois grupos fosfatos pertencentes às camadas inorgânicas subseqüentes. Diferentes graus de protonação do grupo amino terminal são responsáveis por distintas orientações. Desta forma, a condutividade protônica do composto intercalado dependerá do grau de protonação ${ }^{66}$.

A intercalação com aminas cíclicas demonstrou que o aumento no volume ocupado pela molécula hóspede provoca um impedimento estérico nos sítios de intercalação vizinhos. Desse modo, enquanto uma amina primária ocupa $100 \%$ dos sítios disponíveis, as aminas cíclicas ocupam uma menor quantidade de sítios ativos.

As aminas heterocíclicas ou aromáticas são tidas como bases fracas de Br申nsted, logo se torna difícil predizer quando elas estão protonadas e consequentemente, se as interações que ocorreram são dos tipos iônica ou ligação de hidrogênio ${ }^{4}$. Porém, no caso da intercalação de piridazina e pirazol em fosfato de zircônio mostram que estas aminas estão parcialmente protonadas ${ }^{60}$.

Quando estas aminas cíclicas contém também grupos $\mathrm{NH}_{2}$, a protonação provoca um arranjo perpendicular das mesmas em relação à camada inorgânica, com formação de bicamada, como observado para a anilina, benzilamina, 1,4-fenilenodiamina e 2-amino-4-metilpiridina ${ }^{1,80,86,87}$. Já o comportamento muda com as aminas piridina ou pirazina, devido à formação de uma monocamada paralela ao plano da matriz ${ }^{88,89}$. Vale acrescentar que este mesmo aspecto só foi explorado até o momento, na intercalação de piridina em fosfato de titânio na forma $\alpha$, sendo comprovado que a monocamada é formada, antes de atingir a saturação dos sítios ácidos da matriz ${ }^{79}$.

A intercalação de moléculas grandes ou com baixa basicidade necessitam de uma distância interlamelar superior à apresentada pelos fosfatos cristalinos lamelares. O pré-tratamento na matriz com sódio ou monoaminas é um recurso muito utilizado na intercalação de macromoléculas, as quais necessitam de um espaço interlamelar maior para poder difundir, até atingir os sítios ácidos interativos ${ }^{4}$.

Vários macroíons como os complexos de coordenação envolvendo metais ( $\mathrm{Rh}, \mathrm{Pd}, \mathrm{Pt}, \mathrm{Fe}, \mathrm{Cu}$, etc) e fenantrolina, bipiridina, porfirinas substituídas e ftalocianinas foram estudados com as matrizes do tipo $\alpha$ e $\gamma$ fosfatos de zircônio e o tipo $\gamma$ para o fosfato de titânio ${ }^{19,61,90-95}$. Nota-se que, embora, esta já seja uma parte bem explorada na literatura, nenhuma referência é citada para o composto cristalino de titânio, na forma alfa.

Os compostos de coordenação com $\left[\mathrm{Cu}(\text { phen })_{3}\right]^{2+}$, $\left[R h(\text { phen })_{3}\right]^{2+}$ e $\left[R h(\text { bipy })_{3}\right]^{2+}$ podem ser intercalados nos fosfatos pré-tratados ou formados in situ, entre o ligante previamente intercalado na região interlamelar da matriz, que é seguido da complexação com metais de transição ${ }^{61,96}$.

A presença de cátions poliméricos orgânicos ou inorgâni$\cos$ no espaço interlamelar dos fosfatos funciona como pilares que interagem fortemente com as lamelas, gerando um material termicamente estável, com alta área superficial e com grande porosidade, podendo ser utilizado para troca iônica, adsorção e catálise ${ }^{97}$.

O primeiro agente utilizado com material de formação de pilares no espaço interlamelar dos fosfatos de zircônio, titânio e estanho foi o polioxicátion $\left[\mathrm{Al}_{13} \mathrm{O}_{4}(\mathrm{OH})_{24}(\mathrm{OH})_{12}\right]^{7+}$, que é conhecido como íon alumínio de Keggin. Esse polímero aumentou as áreas superficiais dos fosfatos em vinte vezes e provocou um aumento da estabilidade da matriz, até temperaturas superiores a $650 \mathrm{~K}^{97-99}$.

Um método alternativo para criação de poros nos materiais lamelares é a intercalação de siloxano. Os precursores organometálicos são menos utilizados que os íons inorgânicos na química de intercalação em geral e em particular para a pilarização de fosfatos lamelares ${ }^{97}$.

Geralmente, os compostos pilarizados são preparados por troca iônica de espécie polinuclear ou por hidrólise de precursores organometálicos, explorando neste caso o processo sol-gel e portanto, vários fosfatos metálicos pilarizados são assim obtidos ${ }^{84,100-105}$. Dentre eles destacam-se: fosfatos de zircônio ou estanho na forma alfa ( $\alpha$-ZrP e $\alpha$-SnP) pilarizados com sílica e $\alpha$-ZrP pilarizado com alumínio. Entretanto, a intercalação de cátions grandes dentro do espaço interlamelar, muitas vezes resultam em baixo rendimento e baixa cristalinidade do composto pilarizado, como acontece em fosfato de titânio na forma a pilarizado com sílica através do processo de intercalação ${ }^{105}$.

Estes compostos pilarizados são interessantes devido ao grande espaço interpilar, que pode ser visto como um vaso molecular artificial, o qual pode ser ocupado por vários solventes. Algumas reações seletivas podem ser realizadas neste espaço interpilar, especialmente se houver sítios catalíticos presentes sobre a superfície da lamela ou fixado na cadeia alquila, que encontra-se intercalada, sendo considerados, portanto, como reatores moleculares ${ }^{104}$.

\section{AGRADECIMENTOS}

Os autores agradecem a FAPESP pelo apoio financeiro, ao CNPq e a CAPES pelas bolsas recebidas. 


\section{REFERÊNCIAS}

1. Clearfield, A.; Inorganic Ion Exchange Materials, CRC Press, Boca Raton, Florida, 1982.

2. Clearfield, A.; Chem. Rev. 1988, 88, 125.

3. Clearfield, A.; Stynes, J. A.; J. Inorg. Nucl. Chem. 1964, 26, 117.

4. Alberti, G.; Bein, T.; Eds., Comprehensive Supramolecular Chemistry, vol 7, $1^{\text {st }}$ Ed., 1996.

5. Andersen, A. M.; Norby, P.; Inorg. Chem. 1998, 37, 4313.

6. Bruque, S.; Aranda, M. A. G.; Losilla, E. R.; Pastor, P. O.; Torres, P. M.; Inorg. Chem. 1995, 34, 893.

7. Hasegawa, Y.; Akimoto, T.; Kojima, D.; J. Inclusion Phenom. 1995, 20, 1.

8. Okuno, S.; Matsubayashi, Gen-etsu; Inorg. Chim. Acta 1995, 233, 173.

9. Suárez, M.; Rodríguez, M. L.; Llavona, R.; Barcina, L. M.; Vega, A.; Rodríguez, J.; J. Chem. Soc., Dalton Trans. 1997, 163.

10. Kanzaki, Y.; Abe, M.; Bull. Chem. Soc. Jpn. 1991, 64, 1846.

11. Alberti, G.; Galli, P. C.; Costantino, U.; Torraca, E.; J. Inorg. Nucl. Chem. 1967, 29, 571.

12. Alberti, G.; Costantino, U.; Inclusion Compounds, Atwood, J. L.; Davies, J. E. D.; MacNicol, D. D.; Eds., Oxford University Press, New York, 1991.

13. Ferragina, C.; Cafarelli, P.; Giannoccaro, P.; Mater. Res. Bull. 1998, 33, 1635.

14. Christensen, A. N.; Andersen, E. K.; Andersen, I. G. K.; Alberti, G.; Nielsen, N.; Lehmann, M. S.; Acta Chem. Scand. 1990, 8, 865 .

15. Poojary, D. M.; Shpeizer, B.; Clearfield, A.; J. Chem. Soc., Dalton Trans. 1995, 111.

16. Clearfield, A.; J. Mol. Catal. 1984, 27, 251.

17. Nancollas, G. H.; Pekárek, V.; J. Inorg. Nucl. Chem. 1965, 27, 1409.

18. Clearfield, A.; Blessing, R. H.; Stynes, J. A.; J. Inorg. Nucl. Chem. 1968, 30, 2249.

19. Alberti, G.; Costantino, U.; Allulli, S.; Massucci, M. A.; Pelliccioni, M.; J. Inorg. Nucl. Chem. 1973, 35, 1347.

20. Hanzaoni, H.; Batis, H.; J. Phys. Chem. 1992, 89, 85.

21. Lieser, K. H.; Non-siliceous inorganic ion exchangers, Dorfner, K.; Ed., Walter de Gruyter, Berlin, 1991.

22. Airoldi, C.; de Oliveira, S. F.; Structr. Chem. 1991, 2, 41.

23. Airoldi, C.; Roca, S.; J. Mater. Chem. 1996, 6, 1963.

24. Llavona, R.; García, J. R.; Suárez, M.; Rodríguez, J.; Thermochim. Acta 1985, 86, 281.

25. González, E.; Llavona, R.; García, J. R.; Rodríguez, J.; J. Chem. Soc., Dalton Trans. 1989, 829.

26. Kobayashi, E.; Yamazaki, S.; Bull. Chem. Soc. Jpn. 1983, $56,1632$.

27. Alberti, G.; Costantino, U.; Giovagnotti, M. L. L.; J. Inorg. Nucl. Chem. 1979, 41, 643.

28. Alberti, G.; Torraca, E.; J. Inorg. Nucl. Chem. 1968, 30, 317.

29. Slate, R. C. T.; Knowles, J. A.; Jones, D. J.; Rozière, J.; Solidi State Ionics, 1997, 96, 9.

30. Bortun, A.; Jaimez, E.; Llavona, R.; García, J. R.; Rodríguez, J.; Mater. Res. Bull. 1995, 30, 413.

31. Tegehall, P. E.; Acta Chem. Scand. Sect. A 1986, 40, 507.

32. Nunes, L. M.; Airoldi, C.; Thermochim. Acta 1999, 328, 297.

33. Alluli, S.; Ferragina, C.; La Ginestra, A.; Massucci, M. A.; Massini, N.; J. Inorg. Nucl. Chem. 1977, 39, 1043.

34. Alberti, G.; Costantino, U.; Giovagnotti,M. L. L.; Gazz. Chim. Ital. 1980, 110, 61.

35. Alberti G.; Acc. Chem. Res. 1978, 11, 163.

36. Kullberg, L.; Clearfield, A.; J. Phys. Chem. 1981, 85,1585

37. Clearfield, A.; Duax, W. L.; Medina, A. S.; Smith, G. D.; Thomas, J. R.; J. Phys. Chem. 1969, 73, 3424.

38. Clearfield, A.; Smith, G. D.; Inorg. Chem. 1969, 8, 431.

39. Nunes, L. M.; Airoldi, C.; Langmuir 2000, 16, 1436.
40. Roca, S.; Airodi, C.; J. Chem. Soc., Dalton Trans. 1997, 2517.

41. Tegehall, P. E.; Acta Chem. Scand. 1989, 43, 322.

42. Llavona, R.; Suárez, M.; García, J. R.; Rodríguez, J.; Inorg. Chem. 1989, 28, 2863.

43. Ahrland, S.; Albertsson, J.; Acta Chem. Scand. 1964, 18, 1861.

44. Ahrland, S.; Oskarsson, A; Niklasson, A.; J. Inorg. Nucl. Chem. 1970, 32, 2069.

45. Alvarez, C.; Llavona, R.; García, J. R.; Suárez, M.; Rodríguez, J.; Mater. Res. Bull. 1988, 23, 487.

46. Yaroslavtsev, A. B.; Rus. Chem. Rev. 1997, 66, 759.

47. Alberti, G.; Bersasconi, M. G.; Casciola, M.; Costantino, U.; J. Inorg. Nucl. Chem. 1980, 42, 1637.

48. Trobajo, C.; Llavona, R.; Rodríguez, J.; Mater. Res. Bull. 1991, 26, 197.

49. Trobajo, C.; Suárez, M.; García, J. R.; Rodríguez, J.; Solv. Extr. Ion Exch. 1990, 8, 729.

50. Trobajo, C.; Llavona, R.; Rodríguez, J.; Solv. Extr. Ion Exch. 1989, 7, 1089.

51. Menéndez, F.; Rodríguez, M. L.; Trobajo, C.; Suárez, M.; García, J. R.; Rodríguez, J.; Solv. Extr. Ion Exch. 1995, $13,179$.

52. Suárez, M.; Rodríguez, M. L.; Llavona, R.; García, J. R.; Rodríguez, J.; Thermochim. Acta 1995, 249, 367.

53. Salvadó, M. A.; Pertierra, P.; Granda, S. G.; Suárez, M.; Rodríguez, M. L.; Llavona, R.; García, J. R.; Rodríguez, J.; J. Mater. Chem. 1996, 6, 415.

54. González, E.; Llavona, R.; García, J. R.; Rodríguez, J.; J. Chem. Soc., Dalton Trans. 1989, 829.

55. O'Hare, D.; Inorganic Materials; Bruce, D. W.; O'Hare, D.; Eds., 2 ${ }^{\text {nd }}$. Edition, Jonh Wiley, New York, 1997.

56. Schöllhorn, R.; Physica 1980, 98B, 89.

57. Ogawa, M.; Kuroda, K.; Chem. Rev. 1995, 95, 399.

58. Alberti, G.; Costantino, U.; Intercalation Chemistry; Whittinghan, M. S.; Jacobson, A. J.; Eds., Academic Press, New York, 1982.

59. Dines, M. B.; J. Chem. Educ. 1974, 51, 221.

60. Blumenfeld, A. L.; Golub, A. S.; Protsenko, G.; Novikov, N. Y.; Casciola, M.; Costantino, U.; Solid State Ionics 1994, 68, 105.

61. Clearfield, A.; Thakur, D. S.; Appl. Catal. 1986, 26, 1.

62. Ruiz-Hitzky, E.; Adv. Mater. 1993, 5, 334.

63. Fitch, A.; Clays Clay Miner. 1990, 38, 391.

64. Alonzo, G.; Bertazzi, N.; Ferragina, C.; La Ginestra, A.; Massucci, M. A.; Patrono, P.; J. Mater. Chem. 1997, 7, 135.

65. Casciola, M.; Costantino, U.; Solid State Ionics 1994, $68,105$.

66. Casciola, M.; Costantino, U.; Marmottini, F.; Solid State Ionics 1989, 35, 67.

67. Nakayama, H.; Eguchi, T.; Nakamura, N.; Danjo, M.; Tsumako, M.; Nariai, H.; Yamaguchi, S.; Motooka, I.; Bull. Chem. Soc. Jpn. 1997, 70, 1053.

68. Yamanaka, S.; Koizumi, M.; Clays Clay Miner. 1975, 23, 477.

69. Espina, A.; Menéndez, F.; Jaimez, E.; Khainakov, S. A.; Trobajo, C.; García, J. R.; Rodríguez, J.; Chem. Mater. $1998,10,2490$.

70. Costantino, U.; J. Inorg. Nucl. Chem. 1981, 43, 1895.

71. Espina, A.; García, J. R.; Guil, J. M.; Jaimez, E.; Barra, J. P.; Rodríguez, J.; J. Phys. Chem. B 1998, 102, 1713.

72. Espina, A.; Jaimez, E.; Suárez, M.; Trobajo, C.; García, J. R.; Rodrigues, J.; Thermochim. Acta 1992, 210, 263.

73. Espina, A.; Jaimez, E.; Khainakov, S. A.; Trobajo, C.; García, J. R.; Rodrigues, J.; Eur. J. Solid State Inorg. Chem. 1997, 34, 959.

74. Espina, A.; Menéndez, F.; Jaimez, E.; Khainakov, S. A.; Trobajo, C.; García, J. R.; Rodrigues, J.; Mater. Res. Bull. 1998, 33, 763.

75. Espina, A.; Jaimez, E.; Khainakov, S. A.; Trobajo, C.; Rodrigues, J.; J. Mater. Res. 1998, 13, 3304. 
76. Danjo, M.; Kakiguchi, K.; Yanagida, T.; Baba, Y.; Tsuhako, M.; Yamaguchi, S.; Nariai, H.; Motooka, I.; Phosphorus Res. Bull. 1995, 5, 131.

77. Danjo, M.; Baba, Y; Kakiguchi, K.; Tsuhako, M.; Yamaguchi, S.; Hayama, M.; Nariai, H.; Motooka, I.; Bull. Chem. Soc. Jpn. 1995, 68, 1607.

78. Espina, A.; Menéndez, F.; Jaimez, E.; Khainakov, S. A.; Trobajo, C.; García, J. R.; Rodrigues, J.; J. Inclusion Phen. Mol. Recog. Chem. 1998, 30, 333

79. Nunes, L. M.; Airoldi, C.; Chem. Mater. 1999, 11, 2069.

80. Nunes, L. M.; Airoldi, C.; Mater. Res. Bull. 1999, $34,2121$.

81. Nunes, L. M.; Airoldi, C.; J. Solid. State Chem. 2000, $154,557$.

82. Hix, B.; Harris, K. D. M.; Eur. J. Solid State Inorg. Chem. 1997, 34, 589.

83. Lee, C. F.; Thompson, M. E.; Inorg. Chem. 1994, 30, 4.

84. Clearfield, A.; Tindwa, R. M.; J. Inorg. Nucl. Chem. 1979, 41, 871 .

85. Sylvester, P.; Cahill, R.; Clearfield, A.; Chem. Mater. 1994, 6, 1890.

86. Castellón, E. R.; Pastor, P. O.; López, A. J.; Torres, P. M.; Hudson, M. J.; Sylvester, P.; Can. J. Chem. 1989, 67, 2095.

87. Hasegawa, Y.; Seki, H.; Tomita, I.; J. Inclusion Phenom. 1991, 10, 313

88. Yamanaka, S.; Horibe, Y.; Tanaka, M.; J. Inorg. Nucl. Chem. 1976, 38, 323

89. Casciola, M.; Chieli, S.; Costantino, U.; Peraio, A.; Solid State Ionics 1991, 46, 53.

90. Ferragina, C.; La Ginestra, A.; Massucci, M. A.; Mattogno, G.; Patrono, P.; Giannoccaro, P.; Cafarelli, P.; Arfelli, M.; J. Mater. Chem. 1995, 5, 461.
91. Ferragina, C.; Massucci, M. A.; Patrono, P.; La Ginestra, A.; Tomlison, A. A. G.; J. Chem.Soc., Dalton. Trans. 1986, 265.

92. Ferragina, C.; Cafarelli, P.; Di Rocco, R.; Mater. Res. Bull. 1998, 33, 305.

93. Ferragina, C.; La Ginestra, A.; Massucci, M. A.; Patrono, P.; Tomlison, A. A. G.; J. Phys. Chem. 1985, 89, 4762.

94. Li, L.; Liu, X.; Ge, Y.; Liand, L.; Klinoswoki, J.; J. Phys. Chem. 1991, 95, 5910.

95. Hudson, M. J.; Locke, W. J.; Mitchell, P. C. H.; Solid State Ionics 1993, 61, 131.

96. Ferragina, C.; La Ginestra, A.; Massucci, M. A.; Cafarelli, P.; Di Roco, R.; J. Thermal Anal. 1994, 41, 1469.

97. Pastor, P. O.; Torres, P. M.; Castellón, E. R.; López, A. J.; Cassagneau, T.; Jones, D. J.; Rozière, J.; Chem. Mater. 1996, $8,1758$.

98. Clearfield, A.; Roberts, D. B.; Inorg. Chem. 1988, 27, 3237.

99. Pastor, P. O.; López, A. J.; Torres, P. M.; Rodríguez, E. C.; Tomlinson A. A. G.; Alagna, L.; J. Chem. Soc., Chem. Commun. 1989, 751.

100. J. Rozière, D. J. Jones and T. Cassagneau, J. Mater. Chem. 1991, 1, 1081.

101. Robles, J. M. M.; Pastor, P. O.; López, A. J.; Castellón, E. R.; J. Phys. Chem. 1996, 100, 14726.

102.Cassagneau, T.; Jones, D. J.; Rozière, J.; J. Phys. Chem. 1993, 97, 8678.

103. Rodríguez, M. A.; Pastor, P. O.; Castellón, E. R.; López, A. J.; J. Mater. Chem. 1996, 6, 247.

104. Alberti, G.; Mascarós, J. M.; Vivani, R.; J. Am. Chem. Soc. 1998, 120, 9291.

105. Jiao, X.; Chen, D.; Pang, W.; Xu, R.; Yue, Y.; J. Mater. Chem. 1998, 8, 2831. 